\title{
THE UNINTENDED CONSEQUENCES OF SPECIES REINTRODUCTION
}

Ken Kingdon

Box 43

Waskesiu Lake, SK SOJ 2 Y0

ken.kingdon@canada.ca

One of Parks Canada's

fundamental goals is to maintain

Ecological integrity (EI) in

representative protected areas

(National Parks) across the country.

The on-the-ground meaning of ecological integrity is regularly debated by ecologists and Park managers, and is often is in the eye of the beholder. I prefer the simpler view that Parks are considered to have ecological integrity if they have the right species, in the right number, doing (and impacted by) the right thing. While simplistic, my statement suggests that a National Park has El if it has neither too few nor too many of all the native regional species (and no non-native species) while maintaining the natural processes that govern these species, such as predation, fire, drought, and flooding.

Given that many protected areas in southern Canada occur in areas where extensive resource extraction had previously taken place, restoring El can be challenging. A case in point is Riding Mountain National Park (RMNP), where Fisher (Martes pennanti) were re-introduced in 1994. Fisher, like it's close relative the Pine Marten (Martes americana), were originally native to the area of the Park but were heavily trapped throughout the region during the fur trade era, and were considered extirpated, or locally extinct, from RMNP when it was established in 1929. 2,3

Fishers are a mid-sized carnivore belonging to the weasel family, with males having a total length, including the tail, of up to 1 metre, while females are slightly shorter in length. ${ }^{4}$ The average mass of adult female Fishers range from 1.4 to $3.2 \mathrm{~kg}$, while adult males range from 2.7 to $5.4 \mathrm{~kg}$. Unlike the Pine Marten, which prefer conifer stands where they specialise in hunting red squirrels, Fishers are considered to be generalists, and in the Prairie Provinces, they will inhabit both boreal mixed forest and aspen (Populus tremuloides) stands (author, personal observation). Their main prey are Snowshoe Hares, squirrels, and grouse, but also included are small mammals and porcupines.

The reintroduction process into RMNP was relatively straight forward. A study on the feasibility of reintroducing Fisher was conducted by Park staff in 1993. This study relied heavily on previous work that was completed for the assessment of the reintroduction of Pine Marten, that, as mentioned, had also been extirpated from the Park. ${ }^{5}$ The feasibility study included both an analysis of forest cover as well as a small mammal survey, ensuring that the Park had sufficient amounts of habitat and prey to support a newly introduced population. It also relied on expert opinion from trappers and officials from the Province of Manitoba.

The report concluded that both the habitat (vegetation structure) and prey base existed for a successful re-introduction and the plan was approved, and then undertaken in the fall of 1994. Fishers were livetrapped by professional trappers in communities close to the Park boundary, including from the aptly named community of Fisher Branch in Manitoba's Interlake region.

Over two years, a total of 45 animals were introduced, consisting of 24 males and 21 females. Prior to release, all introduced animals were checked by veterinarians, and estimated age and reproductive health were assessed.

The introduction was successful and, by 2000, anecdotal reports of Fisher tracks were recorded by Park staff in most parts of RMNP. During the first formal RMNP winter track survey in 2008, Fisher tracks were located on nearly every transect in the Park. ${ }^{6}$

Within five years of release, Fishers were being captured by trappers on lands adjacent to the Park and by 2005 they made up an important percentage of trapping income for these trappers (Daniel Chranowski. pers. comm.).

The first time that I heard of Fishers leaving the Park was on April 17, 2000. A local resident who lived approximately $2 \mathrm{~km}$ south of the park called me about having a strange animal treed near their residence. It turned out to be a Fisher that had taken refuge in an aspen tree after being chased by the resident's dog. The Fisher remained stationary about 5 metres above the ground and we watched it for about 10 minutes. After the dog was put away and we moved back from the base of the tree, the Fisher vacated the tree and bounded into a stand of small spruce trees, where we quickly lost sight of it.

As a result of the success of the re-introduction program, Park staff began to notice an impact on certain prey species. Of particular interest was the decline in the Park's porcupine population. 
Riding Mountain National Park, with its extensive aspen-white spruce mixed wood forest and abundant willow-lined wetlands, is prime habitat for this species. ${ }^{7}$ This is borne out by observations made by Park staff during the 1970s. During the 10 years between 1970 and 1979, Park wardens were asked to record and report all wildlife sightings. While effort, including miles/kilometres travelled and time spent on the trails was not recorded, porcupines were relatively common, with a total of 269 individuals observed in 236 records. While no formal analysis has been completed on these observations, they represent an average of nearly 27 porcupines/year (ranging from five to 43 ). ${ }^{8}$

In contrast, during the 10 years of winter track survey from 2008 to 2017, no (zero) porcupine tracks were recorded on surveys of trail segments totalling $16.2 \mathrm{~km}$ long up to three different times each year (for a possible total of more than $48 \mathrm{~km}$ ) in different regions of the Park. No live animals were seen during these surveys. ${ }^{6}$

I first noticed the change in the porcupine population by the early 2000s. Beginning with my arrival in the region in 1987, I remember many observations of porcupines in the Park up to 2002. Due to the relative abundance, I generally didn't consider them to be noteworthy, and many of my observations went unrecorded. However, I did record two records of young porcupines prior to, and following, the introduction of Fishers.

The first sighting of note occurred in October 1990, before Fishers were introduced. A young of year porcupine was observed walking toward my then fiancée and I on a trail in RMNP. The porcupine didn't detect us, and walked up to where we were standing on the trail.
Once it noticed our boots, it then looked up at us (reminding us of the opening scene of the Friendly Giant... "look up, look way up"), and then beat a hasty retreat, trundling off down the trail, where we later discovered it poorly hidden in thin brush beside the trail.

My second record occurred on 22 August 1999, five years following the Fisher reintroduction. I observed a female porcupine nursing its young. The adult was covered by a significant amount of white guard hairs, and I initially mistook her for a clump of grass in the sunlight. The young porcupine was black in colour and one-half to three-quarters the size of the adult. The two porcupines were approximately 15 $m$ apart when I first noticed them, and they called to each other with whimpers while moving towards each other. Once together, I assumed the young porcupine was nursing as I could hear sucking sounds, plus sounds of contentment from the young. Nursing was accomplished by the female sitting upright on her haunches, exposing her unprotected belly and chest, allowing her young to approach, presumably without being stabbed by quills. This was my last observation of a live porcupine inside RMNP.

Beginning in the late 1990s, my records indicate finding the remains of porcupines rather than living animals. The first I observed that had been killed by a Fisher was near the Park boundary in 2000, with a second found in the winter of 2002 near the townsite of Wasagaming. Both porcupines had apparently been killed by Fishers, as indicated by the presence of tracks, but also by the tell-tale signs left behind, including the hide and the skinned-out porcupine skulls with relatively small, surgical-like holes in the base of the skull where the Fisher evidently accessed the brains. A third record included the remains of an individual reported by a co-worker on the north shore of Clear Lake on 14 April 2005. The most recent remains of porcupine were discovered on the Park's Arrowhead trail but less than 2 km from the Park boundary, in 2014.

It's important to note that the entire regional porcupine population has not been extirpated. I have observed several porcupines outside the park boundary, including one in 2011, within $200 \mathrm{~m}$ of the boundary. Several have been observed within $1 \mathrm{~km}$ of the park, often grazing in harvested fields. For example, a former Park employee reported seeing two porcupines in a harvested canola field in 2011. Of interest, however, is that these porcupines were occupying habitats - open fields - that Fisher would typically avoid.

A single porcupine was observed inside the Park, walking down one of the access roads on 1 May 2015. As of January 2020, there have been no further reports of live porcupines inside the Park (Sean Frey. pers. comm.).

The possible extirpation of porcupines from RMNP might not be the only unintended consequence of the Fisher reintroduction program. Beginning in about 2000, Park staff began to get reports of domestic cats (Felis catus), primarily kept as barn cats, disappearing from farms adjacent to the Park. Among the first reports was from a warden who lived in a warden station on the north boundary.

On 18 December 2002, Gordon Pylypuik reported that a Fisher captured and killed three house cats in his yard in at the Vermillion Warden Station. "I heard a little activity at 0200 hours. A Fisher came into the yard and in turn hunted down each of my three cats, killing 
them and dragging them east onto Stoney Creek and then south. I couldn't find any remnants of any of the cats, just blood along the trail. I lost the tracks along Stoney Creek as the fresh falling snow obliterated them. The Fisher was likely hauling the kills away and stashing them, as it returned three times." 9

At about the same time, reports of cats disappearing from farms began to be shared with park ecologists, including incidents occurring at the residences of Park staff. The loss of cats around the Park boundary is quite contentious based on conversations with homeowners. The situation is so widespread that it is not known if barn cats can be sustained in areas of contiguous forest linking farms to the Park.

While Fishers appear to have fully adapted to life in RMNP, recent anecdotal reports suggest that the success of Fisher trapping outside the Park has declined slightly over the past several years. ${ }^{6}$

The probability of detecting Fisher on winter track survey routes remains high at approximately 42 per cent. The conclusion of the 2018 annual track survey report is that the Fisher population has peaked, and has reached an equilibrium slightly below the highest numbers observed in the mid 2000s.

The Park's Fisher population reflects a classic population growth curve seen for invasive species. While recognising that Fisher were historically present in the region, their re-introduction acted very much like the introduction of a novel or invasive species. The population growth rate mirrors that of a species moving into a new area, quickly attaining high densities as they fill all available habitat, with high reproductive and survival rates. Once the species exceeds its carrying capacity, increasing intra- specific competition for resources, the population size tends to be reduced to a lower, but dynamic equilibrium. ${ }^{10}$

It is a mystery why porcupines have been extirpated with the re-arrival of Fishers. The range of the two species overlap throughout Canada's boreal forest. ${ }^{5}$ While porcupines could be considered to be naive when re-encountering Fishers for the first time in many generations, there is no reason to believe that they wouldn't quickly adapt to the presence of this historic predator.

I propose that the extirpation of porcupines is the result of the Fisher's initial population growth, and high population in the 2000s. It is possible that high densities of Fishers were able to effectively hunt down and kill all the porcupines within the Park.

If Fishers have now reached an equilibrium population in RMNP at lower levels than the early 2000s, it is possible that a population of porcupines may recolonize the Park. While not necessarily attaining the population levels that existed prior to Fisher re-introduction, porcupines should be able to persist, reflecting the situation in most areas of the Canadian boreal forest.

In conclusion, the reintroduction of Fishers to RMNP has been successful. If porcupines have been pushed to extirpation as a result of it, however, it is a question whether we can claim that RMNP has improved ecological integrity. Only time, and continued surveillance will tell whether a lower Fisher population will allow porcupines to re-establish in RMNP.

\section{Acknowledgements}

I would like to thank Sean Frey and Roger Baird for their work and input into both the winter track monitoring program in RMNP, as well as Sean's quest for collecting and preserving historic species observation databases. I would also like to thank an anonymous reviewer, and the Blue Jay editor, for improving the text and flow of the article.

1. Parks Canada Agency. https://www.pc.gc. ca/en/nature/science/conservation/ie-ei Accessed on-line June 2, 2020.

2. Parks Canada Agency. https://www. pc.gc.ca/en/pn-np/mb/riding/nature/animals/ mammals/marten Accessed online June 2, 2020.

3. Baird Roger (2000) Progress Report Riding Mountain National Park Fisher ReIntroduction Program 1994-95. Unpublished report. Riding Mountain National Park, Parks Canada Agency.

4. Burt William, Grossenheider R. (1976) A Field Guide to the Mammals of America North of Mexico 3rd edition. Houghton Mifflin Company, Boston, MA.

5. Etches Mike (1992) A Study of the Potential Prey Base of the Marten (Martes americana) at the Whirlpool Lake Reintroduction Site in RMNP. Unpublished report. Riding Mountain National Park, Parks Canada Agency.

6. Savage, Arthur and Candace Savage (1981) Wild Mammals of Western Canada. Western Producer Prairie Books, Saskatoon, SK.

7. Baird Roger (2018) Summary Report of the Winter Wildlife Transect Monitoring Program Riding Mountain National Park 2009-2017. Unpublished report. Riding Mountain National Park, Parks Canada Agency.

8. Porcupine Hinterland Who's Who. Canadian Wildlife Federation and Environment and Climate Change Canada. https://www.hww.ca/en/wildlife/mammals/ porcupine.html. Accessed online June 3, 2020.

9. Anonymous (1970-79) CanSYS tracking system historic files. Unpublished data. Riding Mountain National Park.

10. Internal e-mail from Gordon Pylipiuk to Resource Conservation staff dated December 18, 2002.

11. Fleming Peter J S, Ballard G, Reid N, Tracey J (2017) Invasive species and their impacts on agri-ecosystems: issues and solutions for restoring ecosystem processes. The Rangeland Journal 39(6):523-535. 